\title{
ENTREPRENEUR SEBAGAI PILIHAN KARIR MAHASISWI MALUKU UTARA: PERAN EFIKASI DIRI DAN KEPRIBADIAN
}

\author{
Muhammad Rachmat \\ Universitas Khairun, Maluku \\ Email:m.rachmat81@gmail.com
}

\begin{abstract}
Entrepreneurial research among female undergraduate students has become more important these days. This study is to investigate the role of self-efficacy and personality dimension (openness to experience) based on Theory of Planned Behavior. Survey conducted to 117 female students of Maluku Utara. Hypotheses tested using Partial Least Square. The result showed that subjective norm has the stronger relationship with entrepreneur as a career for female undergraduate students. Interestingly, self-efficacy was not significant determinant of entrepreneurial intentions in this study, contrary to earlier studies.
\end{abstract}

Keywords: Entrepreneurial Intention, Self-Efficacy, Personality, Female Undergraduate Students, Maluku Utara

\section{PENDAHULUAN}

Peran dunia pendidikan sangat vital untuk menumbuhkan serta mengembangkan semangat entrepreneur. Pendidikan entrepreneur yang diintegrasikan kedalam sistem pendidikan akan berpotensi mendukung pertumbuhan ekonomi. Berkarier sebagai entrepreneur memberikan sejumlah peluang bagi individual untuk mencapai independensi finansial serta memberikan manfaat bagi ekonomi melalui kontribusinya pada penciptaan lapangan kerja, inovatif, dan pertumbuhan ekonomi (Basu dan Virick, 2008; Nasurdin, et al, 2009).

Peranan entrepreneur perempuan pada aktivitas-aktivitas entrepreneurial cukup signifikan. Perempuan memiliki motivasi tidak berbeda jauh dengan laki-laki dalam aktivitas entrepreneurial (Still dan Stimms, 2000; dalam Gadar dan Yunus, 2009). Riset yang dilakukan oleh MarkPlus Insight (Hasanuddin, et al, 2011; 164) melaporkan bahwa perempuan memiliki semangat berwirausaha yang cukup tinggi, serta menunjukkan lebih dari $60 \%$ perempuan yang disurvei berkeinginan untuk menjadi pengusaha. Mahasiswi (sebagaimana mahasiswa) berpotensi menjadi seorang entrepreneur di masa depan.

Berbagai penelitian telah menjelaskan determinan dari niat pelajar untuk menjadi entrepreneur dengan menggunakan Theory of Planned Behavior (TPB) (misalnya Akmaliah dan Hisyamuddin, 2009; Basu dan Virick, 2008; Li, 2006), efikasi diri (misalnya, Carr dan Sequeira, 2007; Fitzsimmons dan Douglas, 2006; Nasurdin, et al, 2009; Kruger, et al, 2000; Thun dan Kelloway, 2006), dankepribadian(lihat Brandstatter, 2010; Brice, 2004; Gadar dan Yunus, 2009; serta Zhao dan Seibert, 2006)dalam mendorong semangat dan niat entrepreneur.

Dari studi-studi tersebut, dapat diidentifikasi beberapa aspek yang menjadikan riset ini kritikal antara lain: (a) riset yang menganalisis efikasi-diri dan kepribadian pada model niat entrepreneur sangat minim; (b) pada kasus di Indonesia, literatur yang menjelaskan tentang niat mahasiswi (maupun perempuan pada umumnya) menjadi 
entrepreneur masih minim, sehingga riset ini menjadi vital dalam mengembangkan model yang menjelaskan niat entrepreneur yang memasukkan unsur kepribadian dan efikasidiri.Secara khusus, dengan menggunakan TPB, riset ini bertujuan untuk menguji Efikasidiri dan Kepribadian pada niat mahasiswi untuk menjadi Entrepreneur.

\section{KAJIAN TEORI}

Entrepreneur. Entrepreneur dapat diatributkan kepada manajer sebagaimana kepada pendiri bisnis berkenaan dengan kebaruan (novelty) dan kreativitas (Brandstatter, 2010). Entrepreneur ditinjau dari sisi peran (role) adalah individu yang mengambil tanggung jawab dan kepemilikan dalam membuat sesuatu; terbuka dan mampu menciptakan kebaruan; yang mengelola resiko yang melekat pada proses; dan yang memiliki keteguhan, kegigihan, dan ketekunan (persistence) untuk mengidentifikasi tujuan, meskipun menghadapi rintangan-rintangan dan kesulitan-kesulitan (Johnson, 2001, dalam Nasurdin, et al, 2009). Dari perspektif manajemen, entrepreneur adalah individu yang mengorganisasi, memiliki, mengelola, dan mengambil resiko (Cuningham dan Lishcheron, 1991, dalam Nasurdin, et al, 2009). Segal et al (2002) juga berpandangan bahwa entrepreneur adalah seseorang yang bekerja mandiri dan menjalankan, mengorganisasi, dan mengelola, serta bertanggungjawab atas usahanya (Thun dan Kelloway, 2006).

Theory of Planned Behavior (TPB). Berbagai upaya telah dilakukan untuk memahami pentingnya niat menjadi entrepreneur. Kruger, et al (2000) memaparkan bahwa TPB memberikan penjelasan yang berguna untuk memprediksi niat entrepreneur, dan memberikan validitas prediktif yang superior. Lebih lanjut, Kruger, et al (2000) menyebutkan bahwa aktivitas kewirausahaan dapat diprediksi dengan TPB, karena menjadi entrepreneur adalah direncanakan (planned). Penjelasan serupa juga diungkapkan oleh Li (2006), bahwa TPB akan memberikan penjelasan yang berharga dalam memahami niat entrepreneurial.

Perilaku ditentukan oleh niat individu untuk mengerjakan, atau tidak mengerjakan sebuah perilaku. Sementara itu, niat ditentukan oleh sikap terhadap perilaku (attitudes toward behavior), norma subjektif (subjective norm), dan kontrol keperilakuan persepsian (perceived behavioral control) (Ajzen, 1991, dalam $\mathrm{Li}, 2006$ ). Perilaku ditentukan oleh niat berperilaku, sementara niat berperilaku ditentukan oleh sikap individu pada perilaku, persepsi tekanan sosial, serta kontrol keperilakuan persepsian.

TPB secara eksplisit mengidentifikasi tiga anteseden kesikapan dari niat, dua anteseden merepresentasikan keinginan (desirability) untuk melaksanakan suatu perilaku; yakni sikap personal terhadap perilaku serta norma sosial yang dipersepsikan, dan yang ketiga, kontrol keperilakuan persepsian, merefleksikan persepsi kemungkinan (feasibility) akan dilaksanakannya suatu perilaku (Kruger, et al, 2000). Kruger, et al (2000) lebih jauh memaparkan bahwa berdasarkan fakta, niat berperilaku menentukan perilaku, penggunaan niat berperilaku dapat diterima sebagai variabel terikat, dan bahwa niat entrepreneur dikatakan memiliki prediktor ataupun pengukuran yang andal dari perilaku dan aktivitas entrepreneur.

Sejalan dengan TPB, maka niat menjadi entrepreneur didefinisikan sebagai keinginan seseorang untuk bekerja mandiri (selfemployed) atau menjalankan usahanya sendiri (Li, 2006). Thun dan Kelloway (2006) mengoperasionalkan niat entrepreneur sebagai keinginan individu untuk menjalankan bisnisnya sendiri, serta keinginan individu untuk mempertimbangkan entrepreneur sebagai kariernya. Ajzen dan Fishbien (1980) dalam Akmaliah dan Hisyamuddin (2009) mendefinisikan sikap sebagai penilaian seseorang terhadap baik tidaknya dampak dari sebuah perilaku, sementara norma subjektif didefinisikan sebagai tekanan sosial yang dipersepsikan seseorang ketika memilih melakukan suatu tindakan, dan, terakhir kontrol keperilakuan persepsian didefinisikan 
sebagai penilaian individu terhadap kemampuan (ability) untuk mengerjakan perilaku yang diniatkannya.

Berdasarkan TPB, niat dipengaruhi secara positif oleh sikap berperilaku.Dalam hal ini, semakin positif sikap terhadap entrepreneur, maka semakin kuat pula niat untuk menjadi entrepreneur. Jackson dan Rodkey (1994) dalam Akmaliah dan Hisyamuddin (2009) berargumen bahwa sikap terhadap entrepreneurship adalah aspek penting dalam memprediksi potensi entrepreneur di masa mendatang. Kolvereid dan Isaken (2006) juga melaporkan bahwa sikap terhadap bekerjamandiri dapat memprediksi niat bekerjamandiri (Akmaliah dan Hisyamuddin, 2009). $\mathrm{Hal}$ ini telah didukung oleh berbagai temuan empiris yang telah terdokumentasi (misalnya, Akmaliah dan Hisyamuddin, 2009, Basu dan Viric, 2009; Carr dan Sequeira, 2007; Fitzsimmons dan Douglas, 2006; Kruger, et al, 2000), maka hipotesis pertama yang diajukan adalah:

H1: Sikap terhadap Entrepreneur berpengaruh positif pada Niat menjadi Entrepreneur.

TBP juga telah menjelaskan bahwa niat dipengaruhi secara positif oleh norma subjektif.Dalam hal ini, semakin kuat dorongan sosial yang dipersepsikan seseorang ketika memilih melakukan aktivitas entrepreneur, maka semakin memperkuat keinginan individu tersebut untuk bekerja mandiri atau menjalankan usahanya sendiri. Pruett et al (2009) menjelaskan bahwa ikatan keluarga adalah ikatan terkuat yang dimiliki oleh setiap individu, dan ikatan tersebut akan mempengaruhi keputusan dan perilaku. Baughin, et al (2006) dalam Akhmaliah dan Hisyamuddin (2009) melaporkan bahwa dukungan sosial dari keluarga dan teman adalah sumber penting pada keinginan untuk memilih entrepreneur sebagai pilihan karier.

Hal ini telah didukung oleh temuan empiris dari berbagai riset (misalnya, Akmaliah dan Hisyamuddin, 2009; Basu dan Viric, 2009; Carr dan Sequeira, 2007; Gadar dan Yunus, 2009; Kruger, et al, 2000; Nasurdin, et al, 2009). Maka hipotesis kedua yang diajukan adalah.

H2: Norma subjektif berpengaruh positif pada niat menjadi entrepreneur.

Konsep persepsi kontrol keperilakuan sangat berhubungan erat dengan konsep efikasi-diri karena keduanya merujuk pada faktor-faktor yang dipersepsikan secara spesifik pada hasil yang dicapai dari perilaku tertentu (Ajzen, 1987, dalamAkmaliah dan Hisyamuddin, 2009). Kruger, et al (2000) serta Basu dan Virick (2008) jugamenjelaskan bahwa persepsi kontrol keperilakuan berhubungan dengan persepsi kompetensi situasional, dalam hal ini, Efikasi-diri. Kruger dan Carsrud (1993) dalam Akmaliah dan Hisyamuddin (2009) kemudian merekomendasikan efikasi-diri entrepreneur untuk menggantikan persepsi kontrol keperilakuan yang juga memprediksi niat menjadi entrepreneur.

Efikasi Diri. Efikasi-diri telah dihubungkan secara teoritis dan empiris dengan berbagai fenomena manajerial maupun entrepreneurial (Krueger, et al, 2000). Efikasi-diri entrepreneur (entrepreneur self-efficacy) berperan pada peningkatan pengembangan niat entrepreneurial (Fitzsimmons dan Douglas, 2006). Efikasi-diri entrepreneur didefinisikan sebagai keyakinan individual bahwa mereka memiliki kemampuan untuk mengerjakan tugas yang berkaitan dengan entrepreneurship (Fitzsimmons dan Douglas, 2006; Hmieleski dan Baron, 2008) dan keyakinan kognitifnya tentang kemampuankemampuan ini (Fitzsimmons dan Douglas, 2006).

Dalam beberapa tahun belakangan, efikasi-diri telah memperoleh perhatian sebagai faktor kunci dalam menjelaskan mengapa beberapa orang termotivasi untuk menjadi entrepreneur sedangkan yang lain tidak (Muller dan Dato-On, 2008). Kemampuan tugas-spesifik dalam hubungan dengan entrepreneurship digambarkan ke dalam konstruk efikasi-diri entrepreneur sebagai anteseden kunci dari niat entrepreneur (Fitzsimmons dan Douglas (2006). Bandura (1991) dalam Thun dan Kelloway (2006) jugamendeskripsikan bahwa 
efikasi-diri entrepreneur adalah elemen kunci baik untuk respons efektif maupun keperilakuan dalam sistem self-monitoring.

Individu dengan efikasi-diri yang tinggi cenderung untuk menetapkan tujuan-tujuan yang menantang, dan berusaha sekuat tenaga untuk mencapai tujuan tersebut, bahkan dalam situasi yang sulit dan penuh stres, lebih cepat bangkit dari kegagalan, bahkan dalam kondisi yang sangat merugikan (Bandura, 1977, dalamHmielski dan Baron, 2008). Seorang entrepreneur memiliki efikasidiri yang tinggi dan sungguh-sungguh yakin dengan kemampuannya untuk mengeksekusi seluruh kebutuhan untuk menyelesaikan tugas-tugas baru dengan sukses (Bandura, 1997, dalamKumar dan Uzkhurt, 2009), sederhananya, individu dengan tingkat efikasidiri yang tinggi cenderung untuk bekerja keras untuk mencapai tujuannya (Indarti, et al, 2010).

Semakin tinggi efikasi-diri dari seorang entrepreneur akan berkontribusi pada pandangannya dalam melihat outcome positif yang mungkin terjadi pada usaha yang baru dan mengejar tujuan tersebut dengan semangat (Kumar dan Uzkhurt, 2009), dan tanpa tingkatan minimal dari efikasi-diri entrepreneur, boleh jadi,calon entrepreneur kurangmemiliki motivasi dalam melaksanakan proses kreatif dalam usaha baru (Hmieleski dan Baron, 2008). Thun dan Kelloway (2006) menjelaskan efikasi-diri entrepreneur sebagai prediktor niat entrepreneur yang cukup kuat. Chen, et al (1998) dalam Hmieleski dan Baron (2008) melaporkan bahwa efikasi-diri entrepreneur berhubungan positif dengan niatnya untuk memulai proses penciptaan usaha baru, demikian pula Einrich (1999) dalam Akmaliah dan Hisyamuddin (2009) yang mengkonfirmasi bahwa individu dengan efikasi-diri entrepreneur yang tinggi juga memiliki niat untuk menjadi entrepreneur yang tinggi pula. Betz dan Hacket (1994) dalam Indarti, et al (2010) menegaskan bahwa semakin tinggi tingkatan efikasi-diri pada tahapan awal karir entrepreneur, semakin kuat niat entrepreneurnya. Hipotesis ketiga yang diajukan adalah:
H3: Efikasi-diri entrepreneur berpengaruh positif pada niat untuk menjadi entrepreneur.

Kepribadian. Keyakinan bahwa entrepreneur memiliki karakteristik (trait) psikologi yang istimewa telah lama menjadi tradisi pada riset entrepreneurship (Brice, 2004). Variabel-variabelkepribadian boleh jadi memiliki peran penting dalam mengembangkan teori proses entrepreneurial, termasuk di dalamnya niat berkarier sebagai entrepreneur (Zhao dan Seibert, 2006). Lebih jauh, Zhao dan Seibert (2006) mengindikasikan bahwa riset yang memeriksa peran kepribadian dalam entrepreneurial menunjukkan jumlah yang cukup substansial. Big-Five Personality telah digunakan secara luas dalam psikologi industri sebagai dasar untuk mengukur sikap-sikap terkait pekerjaan (job-related attitudes), kecocokan personalorganisasional, dan keperluan sumberdaya manusia lainnya (Brice, 2004).Brice (2004) menjelaskan bahwa faktor-faktor kepribadian yang membentuk Big-Five antara lain: (1) Extraversion, (2) Agreebleness, Conscientiousness, (4) Neuroticism (juga dikenal dengan emotional stability), serta (5) Openness to experience. Brice (2004) jugamenegaskan bahwa dimensi kepribadian boleh jadi stabil sepanjang waktu dan bukti empiris ini seharusnya memberikan arah untuk mengaplikasikan dimensi kepribadian untuk mengidentifikasi kategori kepribadian bagi kelompok-kelompok dari individualindividual dalam populasi.

Studi meta-analysis yang dilakukan oleh Zhao dan Siebert (2006) kemudian studi lainnya oleh Brice (2004) melaporkan bahwa Conscientiousness dan Openness to Experience (OE) ditemukan lebih kuat pada entrepreneur daripada pada manajer, serta lebih kuat memprediksi niat entrepreneurial daripada dimensi kepribadian lainnya. Zhao dan Siebert (2006) berpendapat bahwa OE cenderung berperan penting pada fase persiapan memulai entrepreneurial ketika aktivitas mengenali peluang adalah aktivitas yang kritis. Mengingat riset ini dilakukan pada domain niat berperilaku dan bukan kepada perilaku aktual, maka berdasarkan atas 
temuan Brice (2004) serta argumentasi dari Zhao dan Siebert (2006), OE dipilih untuk dianalisis lanjut.

OE dideskripsikan sebagai keluasan, kedalaman, orijinalitas dan kompleksitas dari mental individu (Brandsatter, 2010). OE didefinisikan oleh Brice (2004) sebagai kecenderungan (propensity) memiliki rasa ingintahu yang tinggi, kreatif, tidak biasa, dan independen. Zhao dan Siebert (2006) menjelaskan bahwa OE adalah dimensi kepribadian yang mengkarakteristik seseorang yang memiliki rasa ingin tahu intelektual dan cenderung untuk mencari pengalaman baru dan mengeksplorasi ide-ide baru (novelty). Lebih lanjut, Zhao dan Siebert (2006) mendeskripsikan bahwa OE dapat digambarkan sebagai seseorang yang kreatif, inovatif, imajinatif, reflektif, dan tidak biasa. Nilai-nilai OE inilah yang seringkali merefleksikan semangat entrepreneurship yang kuat (Brice, 2004). Kirzner (1993) dalam
Brice (2004) menjelaskan bahwa individu yang terbuka untuk menjalani hal-hal baru sangat ingintahu dan bersedia untuk merealisasikan ide-ide baru dan nilai-nilai yang tidak umum, dan oleh karenanya, individu cenderung untuk tidak tertarik kepada peran pekerjaan tradisional dan karier tradisional (menjadi karyawan). Zhao dan Siebert (2006) memaparkanbahwa menjalankan ide baru atau mendirikan usaha baru sepertinya memerlukan entrepreneur untuk mengeksplorasi ide-ide baru (new and novel), dan menggunakan kreativitasnya untuk mengatasi masalah-masalah baru (new and novel) serta menggunakan pendekatan yang inovatif terhadap produk, metodemetode bisnis, ataupun terhadap strategistrategi. Hipotesis ke-empat yang diajukan adalah.

H4: OE berpengaruh positif pada niat untuk menjadi entrepreneur.

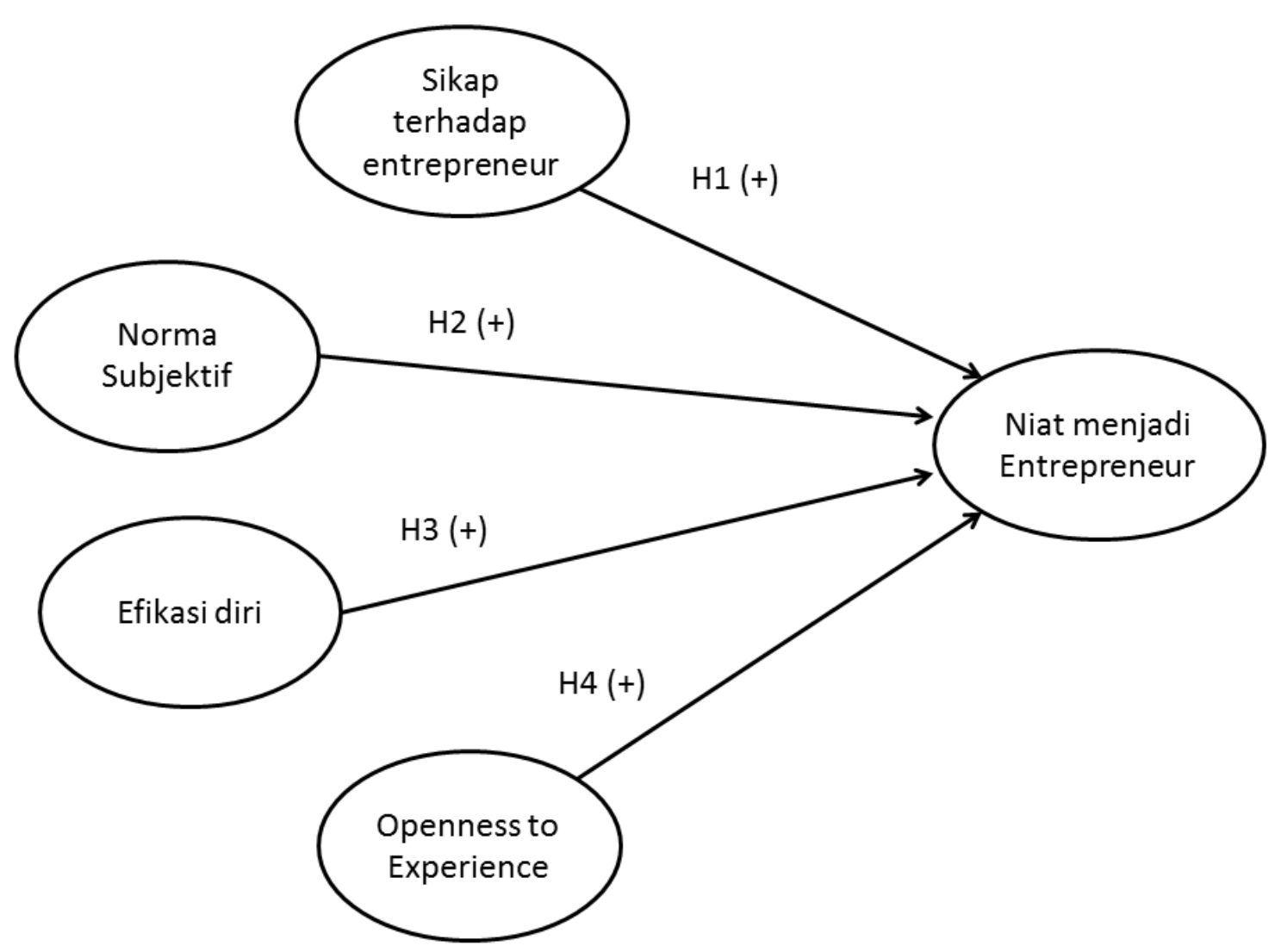

Gambar 1. Model yang Diajukan

Sumber: Akmaliah dan Hisyamuddin (2009), serta Brice (2004), dengan penyesuaian. 


\section{METODE PENELITIAN}

Responden dan Pengumpulan Data. Responden dalam riset ini adalah mahasiswi pada Universitas Khairun dan Universitas Muhammadiyah Maluku Utara. Faktanya, mahasiswa pada kedua Universitas ini datang dari berbagai etnik di Maluku Utara dan oleh karenanya, merepresentasikan mahasiswi di Maluku Utara.

Pengumpulan data dilakukan melalui kuesioner menggunakan convenience sampling. Convenience sampling termasuk teknik penyampelan nonprobability, teknik ini memberi peneliti kebebasan dalam memilih responden yang sesuai (Cooper dan Schindler, 2008:397). Kuesioner disebar kepada 215 (dua ratus lima belas) orang mahasiswi. Dari jumlah tersebut, kuesioner yang bisa digunakan berjumah 117 (seratus tujuh belas) buah. Berdasarkan uji post-hoc menggunakan program G*Power 3.0.10 (Faul, et al, 2007) menghasilkan power sebesar 0.926183 melebihi 0,80 sebagaimana yang disyaratkan oleh Hair et al (2006:11-12).

Definisi Operasional dan Pengukuran. Niat menjadi entrepreneur didefinisikan sebagai keinginan seseorang untuk bekerja mandiri atau menjalankan usahanya sendiri, dan diukur menggunakan 11 item pertanyaan yang diadaptasi dari Akmaliah (2009). Sikap terhadap entrepreneur didefinisikan sebagai penilaian individu terhadap dampak dari baik tidaknya menjadi entrepreneur, dan diukur menggunakan 4 item pertanyaan yang diadaptasi dari Carr dan Sequeira (2007). Norma Subjektif didefinisikan sebagai dukungan sosial yang dipersepsikan seseorang ketika memilih melakukan aktivitas entrepreneur dan diukur menggunakan 3 item pertanyaan yang diadaptasi dari Nasurdin, et al (2009). Efikasi-diri Entrepreneur didefinisikan sebagai keyakinan individual pada kemampuannya untuk mengerjakan tugas yang berkaitan dengan entrepreneurship dan diukur menggunakan 3 item pertanyaan yang diadaptasi dari Akmaliah (2009). OE didefinisikan sebagai kecenderungan memiliki rasa ingintahu yang tinggi, kreatif, tidak biasa, dan independen, dan diukur menggunakan 10 item pertanyaan yang diadaptasi dari John dan Srivastava (1991).

Metode Analisa Data. Metode analisis yang digunakan adalah SEM berbasis komponen (component-based) dengan program SmartPLS Ver.2.M3 (Hansmann dan Ringle, 2004). Partial Least Square (PLS) adalah metode analisis yang kuat karena tidak banyak persyaratan atas skala pengukuran, serta PLS dapat digunakan untuk konfirmasi teori dan PLS bisa digunakan untuk menjelaskan hubungan yang sangat kompleks (Chin et al, 1996).

\section{HASIL DAN PEMBAHASAN}

Profil Responden. Responden dalam riset ini adalah mahasiswi yang berusia $17-29$ tahun, dengan rata-rata usia adalah 20,22 tahun dengan deviasi 1,894 tahun. Sebanyak $52,1 \%$ berasal dari luar Ternate, 52,1\% berasal dari Universitas Muhammadiyah Maluku Utara, sebanyak $54,7 \%$ dan memiliki keluarga dengan latar belakang bukan entrepreneur (tabel 1).

Statistik Deskriptif. Statistik deskriptif memuat nilai rata-rata, deviasi standar dan korelasi dari masing-masing konstruk (tabel2).

Dapat dilihat pada tabel 2, bahwa korelasi Sikap terhadap Entrepreneur, Norma Subjektif, dan OE pada Niat menjadi Entrepreneur berada pada tingkat moderat dan signifikan $(p<0,01)$. Sementara EfikasiDiri berkorelasi lemah meskipun signifikan $(p<0,01)$. Tabel 2 juga menginformasikan bahwa rata-rata nilai berkisar antara 3,524 4,325 dan standar deviasi antara 0,592 0,849 . Nilai-nilai tersebut dapat dikategorikan sebagai rendah $(<3,39)$, moderat $(3,40-3,79)$, dan tinggi $(>3,80)$ (Akhmaliah, 2009). Berdasarkan kategori tersebut, dapat dilihat bahwa persepsi niat mahasiswi untuk menjadi seorang entrepreneur, norma subjektif, serta efikasi diri berada pada level moderat, sementara persepsi mahasiswi akan faktor personal dan kepribadiannya untuk terbuka pada pengalaman-pengalaman baru berada pada level tinggi. 
Tabel 1: Profil Responden

\begin{tabular}{clccc}
\hline & & & $\mathrm{N}$ & $\%$ \\
\hline \multirow{3}{*}{ Usia } & Minimum & 17 & 117 & 100 \\
& Maximum & 29 & & \\
& Mean & 20,22 & & \\
& Std. Deviation & 1,894 & & \\
\hline \multirow{2}{*}{ Etnik } & Ternate & & 56 & 47,9 \\
& Selain Ternate & 61 & 52,1 \\
\hline Perguruan & Unkhair & 56 & 47,9 \\
Tinggi & UMMU & 61 & 52,1 \\
\hline Latar Keluarga & Bukan Entrepreneur & 64 & 54,7 \\
& Entrepreneur & & 53 & 45,3 \\
\hline
\end{tabular}

Sumber: data primer, diolah.

Tabel 2: Statistik Deskriptif

\begin{tabular}{lccccccc}
\hline & Mean & SD & 1 & 2 & 3 & 4 & 5 \\
\hline $\begin{array}{l}\text { Niat Menjadi } \\
\text { Entrepreneur }\end{array}$ & 3,59096 & 0,84867 & 1 & & & & \\
\hline $\begin{array}{l}\text { Sikap terhadap } \\
\text { Entrepreneur }\end{array}$ & 4,32479 & 0,59203 &, $384^{* *}$ & 1 & & & \\
\hline Norma Subjektif & 3,48433 & 0,7562 &, $449^{* *}$ &, $371^{*}$ & & 1 & \\
\hline $\begin{array}{l}\text { Openess-to- } \\
\text { Experience (OE) }\end{array}$ & 3,90598 & 0,61284 &, $351^{* *}$ &, $273^{* *}$ &, $425^{* *}$ & 1 & \\
\hline Efikasi-Diri & 3,52422 & 0,8098 &, $285^{* *}$ &, 154 &, $553^{* *}$ &, $555^{* *}$ & 1 \\
\hline
\end{tabular}

${ }^{* *}$. Correlation is significant at the 0.01 level (1-tailed).

*. Correlation is significant at the 0.05 level (1-tailed).

Sumber: data primer, diolah

Validitas \& Reliabilitas. Pengujian pertama menunjukkan bahwa N8 s/d N11 demikian pula dengan item OE1, OE2, OE3, OE9 dan OE10 memiliki nilai loading di bawah yang disyaratkan, yakni 0,7 . Maka item-item ini tidak diikutkan pada analisis selanjutnya. Kecuali pada item OE4, OE6, OE7 yang nilainya mulai dari $0,68-0,69$, atas pertimbangan bahwa nilai ini sangat dekat dengan nilai yang disyaratkan, maka itemitem ini dipertahankan. Menurut Chin et al (1996) serta Hair et al (2006:777), nilai loading 0,5-0,6 bisa tetap dipertahankan dalam analisis.

Uji validitas menunjukkan bahwa seluruh item Niat (N), Norma Subjektif (NS), Sikap (S) dan Efikasi Diri (SE) memiliki nilai loading 0,698 sampai dengan 0,888 dan signifikan pada alpha $5 \%$, serta nilai AVE di atas 0,5 (Tabel 3). Hasil pengujian juga menunjukkan bahwa nilai akar kuadrat AVE lebih tinggi daripada nilai korelasi pada setiap konstruk laten (Tabel 3). Dari hasil uji dapat disimpulkan bahwa seluruh item pengukuran yang digunakan dalam penelitian ini memiliki validitas konvergen dan validitas diskriminan yang baik (valid) sesuai kriteria yang diajukan oleh Gefen dan Straub (2005). Hasil pengujian reliabilitas menunjukkan seluruh konstruk memberikan nilai Cronbach's alpha dan nilai Composite Reliability di atas 0,80 (Tabel 3) sesuai dengan ketentuan Hair et al (2006:139). Dapat disimpulkan bahwa seluruh instrumen penelitian memiliki reliabilitas yang baik.

Goodness of Fit Model. Untuk pengukuran global fit dari model, Tenenhaus et al (2005) mengajukan pengukuran dengan rumus:

Goodness of Fit $(\mathrm{GoF})=\sqrt{\overline{\mathrm{C}} \quad \mathrm{X} \quad \overline{\mathrm{R}^{2}}}$

$$
\begin{array}{lll}
\bar{C} & =\text { Nilai rata-rata Communality } \\
\overline{R^{2}} & =\quad \text { Nilai rata-rata R-Square }
\end{array}
$$

Schepers et al (2005) mengelompokkan nilai GoF kedalam kategori kecil $(0,1)$, medium $(0,25)$ dan besar $(0,36)$. Berdasarkan kriteria Schepers et al (2005), maka model penelitian ini dapat dikategorikan sebagai model dengan kesesuaian yang baik (GoF = $0,4486>0,36$. Tabel 4). 
Tabel 3: Nilai Loading, t-hitung, CR, CA, AVE, dan Akar Kuadrat AVE

\begin{tabular}{|c|c|c|c|c|c|c|}
\hline Item & Loading & t-hitung & CR & $\mathrm{CA}$ & AVE & Square Root AVE \\
\hline N1<- Ent_Intention & 0,835 & 23,661 & 0,936 & 0,919 & 0,676 & 0,825 \\
\hline N2 <- Ent_Intention & 0,812 & 23,358 & & & & \\
\hline N3 <- Ent_Intention & 0,858 & 35,916 & & & & \\
\hline N4 <- Ent_Intention & 0,888 & 44,101 & & & & \\
\hline N5 <- Ent_Intention & 0,843 & 35,425 & & & & \\
\hline N6 <- Ent_Intention & 0,789 & 22,332 & & & & \\
\hline N7 <- Ent_Intention & 0,720 & 14,289 & & & & \\
\hline NS1 <- Subjective Norm & 0,847 & 18,487 & 0,872 & 0,780 & 0,695 & 0,833 \\
\hline NS2 <- Subjective Norm & 0,860 & 23,807 & & & & \\
\hline NS3 <- Subjective Norm & 0,792 & 16,233 & & & & \\
\hline OE4 <- Openess & 0,698 & 10,688 & 0,871 & 0,834 & 0,576 & 0,759 \\
\hline OE5 <- Openess & 0,755 & 15,455 & & & & \\
\hline OE6 <- Openess & 0,785 & 20,172 & & & & \\
\hline OE7 <- Openess & 0,773 & 16,207 & & & & \\
\hline OE8 <- Openess & 0,780 & 15,865 & & & & \\
\hline S1 <- Attitude TE & 0,823 & 16,994 & 0,895 & 0,847 & 0,681 & 0,825 \\
\hline S2 <- Attitude TE & 0,808 & 13,957 & & & & \\
\hline S3 <- Attitude TE & 0,852 & 27,242 & & & & \\
\hline S4 <- Attitude TE & 0,818 & 22,447 & & & & \\
\hline SE1 <- Self-Efficacy & 0,869 & 20,514 & 0,897 & 0,834 & 0,744 & 0,862 \\
\hline SE2 <- Self-Efficacy & 0,842 & 12,968 & & & & \\
\hline SE3 <- Self-Efficacy & 0,876 & 27,981 & & & & \\
\hline
\end{tabular}

Keterangan: $\mathrm{CR}=$ Composite Reliability; $\mathrm{CA}=$ Cronbach Alpha.

Sumber: output SmartPLS, diolah.

Tabel 4: Goodness of Fit Model

\begin{tabular}{lcc}
\multicolumn{1}{c}{ Variabel } & R Square & Communality \\
\hline Sikap Terhadap Entrepreneur & & 0,681 \\
\hline Niat Menjadi Entrepreneur & 0,2984 & 0,676 \\
\hline OE & & 0,576 \\
\hline Efikasi Diri & 0,744 \\
\hline Norma Subjektif & 0,2984 & 0,695 \\
\hline Rerata & & 0,6743 \\
\hline \multicolumn{1}{c}{ Goodness-of-Fit } & 0,4486 \\
\hline
\end{tabular}

Pengujian Hipotesis dan Diskusi. Dari hasil pengujian (tabel5), Koefisien jalur antara sikap terhadap entrepreneur dan niat menjadi entrepreneur adalah signifikan pada 5\% $(0,2477, p<0,05)$. Ini berarti secara statistik, sikap terhadap entrepreneur berpengaruh positif dan signifikan pada niat menjadi entrepreneur. Hipotesis pertama terdukung.Temuan ini mengkonfirmasi risetriset sebelumnya (misalnya, Akmaliah dan Hisyamuddin, 2009, Basu dan Viric, 2009; Carr dan Sequeira, 2007; Fitzsimmons dan Douglas, 2006; Kruger, et al, 2000). Hal ini bermakna bahwa mahasiswi memberikan penilaian yang baik terkait dampak menjadi enrepreneur yang menguatkan keinginannya untuk menjalankan usahanya sendiri. Dengan kata lain, semakin positif evaluasi tersebut maka niatnya untuk menjalankan usahanya sendiri menjadi terkuatkan.

Koefisien jalur antara norma subjektif dan niat menjadi entrepreneur adalah signifikan pada $5 \%(0,2826, p<0,05)$. Ini berarti secara statistik, norma subjektif berpengaruh positif dan signifikan pada niat menjadi entrepreneur. Hipotesis kedua terdukung.Temuan ini mengkonfirmasi riset-riset sebelumnya (misalnya, Akmaliah dan Hisyamuddin, 2009; Basu dan Viric, 2009; Carr dan Sequeira, 2007; Gadar dan Yunus, 2009; Kruger, et al, 2000; Nasurdin, et al, 2009; Pruett et al, 2009). Hal ini bermakna bahwa ada dukungan sosial yang kuat kepada mahasiswi untuk memilih menjalani karirnya sebagai seorang entrepreneur. Dorongan tersebut berasal dari keluarga dekat, teman dekat, dan orang-orang 
penting menurut si mahasiswi yang kemudian menguatkan niatnya untuk menjalankan usahanya sendiri. Temuan ini memberikan indikasi bahwa dukungan sosial dari keluarga dan teman adalah sumber penting pada keinginan untuk memilih entrepreneur sebagai pilihan karier. Menurut Ismail, et al (2009), dukungan dari keluarga dan teman menjadi penting karena ketika menamatkan kuliahnya, pendanaan wirausaha yang paling mungkin adalah diperoleh dari keluarga dan teman, dan bukannya dari pinjaman bank. Di sisi lain, dalam budaya kolektif dan keeratan kekeluargaan seperti yang dimiliki oleh masyarakat Maluku Utara, dukungan keluarga dan teman sangat dimungkinkan dalam memberikan dampak bagi niat untuk menjadi entrepreneur; dan hal ini sejalan dengan Pruett, et al (2009) yang menegaskan bahwa ikatan keluarga adalah ikatan terkuat yang dimiliki oleh seseorang.

Koefisien jalur antara efikasi diri dan niat menjadi entrepreneur adalah tidak signifikan pada $5 \%(0,0273, p>0,05)$. Ini berarti secara secara statistik, efikasi diri tidak berpengaruh signifikan pada niat menjadi entrepreneur. Hipotesis ketiga tidak terdukung. Berbeda dengan literatur sebelumnya yang telah menunjukkan bahwa Efikasi Diri memiliki pengaruh signifikanpada Niat menjadi Entrepreneur, riset ini tidak menemukan bukti untuk mengkonfirmasi hal tersebut. Fitzsimmons dan Douglas (2006) mengkonfirmasi temuan ini, demikian pula dengan Indarti, et al (2010) pada kasus mahasiswa Jepang. Dalam konteks riset ini, dapat disimpulkan bahwa mahasiswi Maluku Utara tidak memiliki keyakinan diri atas kemampuannya (seperti kemampuan manajerial, mengelola keuangan dan pemasaran) yang cukup kuat untuk menstimulasi dirinya menjadi entrerpreneur setelah menyelesaikan sekolahnya. Luthans dan Ibrayeva (2006) menjelaskan bahwa efikasi diri ditentukan oleh karakter personal entrepreneur yang dicirikan dengan keinginan untuk sukses dan keyakinan bahwa untuk kesuksesannya berada pada dirinya sendiri.

Koefisien jalur antara OE dan niat menjadi entrepreneur adalah signifikan pada $5 \%$ $(0,1593, p<0,05)$. Ini berarti secara statistik, OE berpengaruh positif dan signifikan pada niat menjadi entrepreneur. Hipotesis keempat terdukung.Hal ini mengkonfirmasi literatur terdahulu yang menemukan bahwa $\mathrm{OE}$ berpengaruh positif dan signifikan pada Niat menjadi Entrepreneur (misalnya Brice, 2004; Zhao dan Siebert, 2006), yang bermakna bahwa mahasiswi Maluku Utara memiliki rasa ingintahu yang tinggi, kreatif, tidak biasa, dan independen (Mean=3,90598, SD=0,61284) mampu mendorong keinginannya untuk menjalankan usahanya sendiri. Temuan ini menguatkan dugaan Zhao dan Siebert (2006) bahwa dimensi kepribadian OE berdampak positif dalam fase awal aktifitas entrepreneurial. Tampaknya, imajinasi aktif, berdaya cipta, minat berkreasi, menghargai pengalaman-pengalaman berkreasi serta suka memberikan ide-ide adalah hal-hal merefleksikan semangat entrepreneurship yang kuat. Mahasiswi yang memiliki rasa ingin tahu yang tinggi akan mengeksploitasi kreatifitasnya untuk mewujudkan ide baru dan tidak umum serta menggunakan pendekatan yang inovatif akan cenderung tidak tertarik pada pekerjaan sebagai seorang karyawan.

Jika membandingkan kekuatan pengaruh (magnitude), maka dapat dilihat bahwa norma subjektif memiliki pengaruh yang cukup kuat daripada tiga variabel lainnya, dengan pengaruh sebesar 0,2826 (3,019; $\mathrm{p}<1 \%)$. Akhmaliah dan Hisyamuddin (2009) juga menemukan hal serupa.

Tabel 5: Pengujian Hipotesis

\begin{tabular}{lcccc}
\hline \multicolumn{1}{c}{ Hipotesis } & Koefisien & t-hitung & $\boldsymbol{P}$ & Keterangan \\
\hline Sikap terhadap Entrepreneur --> Niat menjadi entrepreneur & 0,2477 & 3,7256 & 0,000 & terdukung \\
\hline Norma Subjektif --> Niat menjadi entrepreneur & 0,2826 & 3,0192 & 0,001 & terdukung \\
\hline Efikasi Diri --> Niat menjadi entrepreneur & 0,0273 & 0,4331 & 0,333 & tidak terdukung \\
\hline Openess to Experience --> Niat menjadi entrepreneur & 0,1593 & 1,9566 & 0,025 & terdukung \\
\hline
\end{tabular}

Sumber: Output PLS, diolah. 


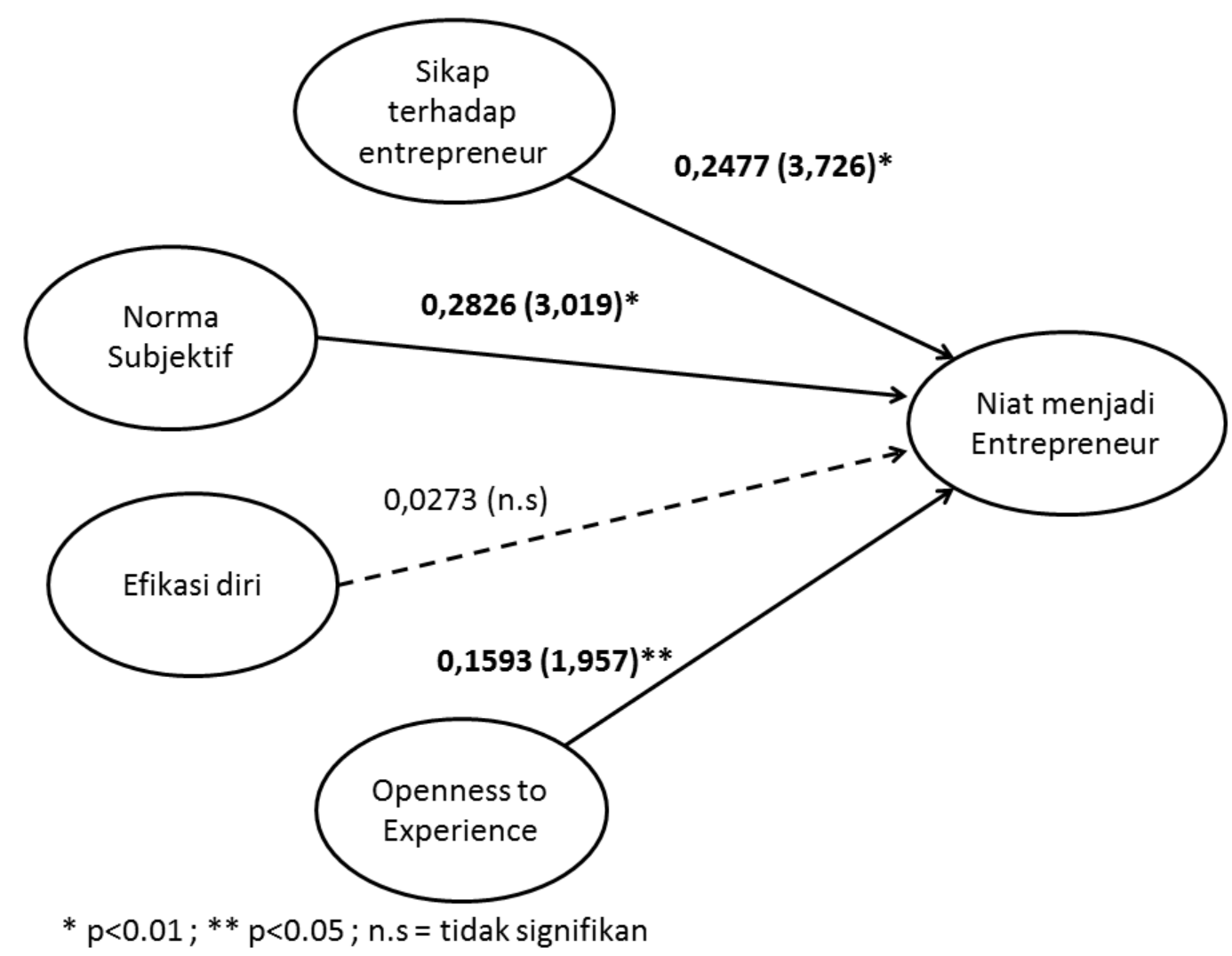

Gambar 2. Model Empiris

\section{KESIMPULAN}

Dari analisa data dan diskusi dapat disimpulkan bahwa:

1. Sikap terhadap Entrepreneur berpengaruh positif dan signifikan pada Niat menjadi Entrepreneur.

2. Norma Subjektif berpengaruh positif dan signifikan pada Niat menjadi Entrepreneur.

3. Pengaruh Efikasi Diri ditemukan tidak signifikan pada Niat menjadi Entrepreneur.

4. OEditemukan berpengaruh positif dan signifikan pada Niat menjadi Entrepeneur.

5. Norma Subjektif memiliki pengaruh yang lebih besar daripada variabel lainnya dalam riset ini.

6. OE lebih berperan dalam pembentukan Niat Mahasiswi di Maluku Utara untuk menjadi Entrepreneur daripada Efikasi-diri.

Implikasi Praktik. Hasil penelitian ini telah memberikan kerangka kerja bagi dunia pendidikan mengenai bagaimana menumbuhkembangkan dan memelihara semangat entrepreneur; yakni dengan mendisain kurikulum kewirausahaan yang berbasis pada penguatan keyakinan atas kemampuan diri serta pada penguatan hal-hal yang merefleksikan semangat entrepreneurship yang kuat diantaranya penguatan keaktifan imajinasi, penguatan daya cipta dan minat berkreasi, penghargaan kepada pengalaman-pengalaman berkreasi serta memberi penguatan melalui dukungan sosial (keluarga, teman, dan tokoh penting).

Implikasi Teoritis. Riset ini telah menambahkan bukti empiris baru mengenai mengapa mahasiswi berniat menjadi entrepreneur. Menariknya, pada mahasiswi, efikasi-diri ternyata tidak berpengaruh pada Niat menjadi Entrepreneur. Hal ini tentunya memerlukan studi lanjutan yang mendalam untuk mendapatkan pemahaman yang lebih baik.

Keterbatasan dan Arahan Riset Mendatang. Riset ini memiliki keterbatasan antara lain responden adalah mahasiswi bukan hanya pada tingkat akhir studi sehingga belum secara kuat menangkap fenomena. Di sisi lain, riset ini menggunakan non-probability sampling, yang kemungkinan memberikan bias pada generalisasi hasil riset. 
Riset ini didesain sebagai cross-section study sehingga memiliki keterbatasan pada apakah dalam jangka panjang variabel prediktor (norma subjektif / dukungan sosial, sikap terhadap entrepreneur, efikasi diri dan OE) mampu mengubah niat menjadi perilaku entrepreneur.

Atas keterbatasan-keterbatasan di atas, maka riset mendatang disarankan untuk membatasi responden pada mahasiswa tingkat akhir agar menangkap fenomena dengan lebih kuat. Riset mendatangjuga perlu didesain sebagai longitudinal-study agar mampu memotret setiap tahapan entrepreneur secara lebih luas.

\section{REFERENSI}

Akmaliah, Z., (2009),"Entrepreneurship as a Career Choice: An Analysis of Entrepreneurial Self-Efficacy and Intentions of University Students", European Journal of Social Research, Vol.9(2), pp.338-349.

Akmaliah, Z., dan H. Hisyamuddin (2009),"Choice of Self-Employment Intentions Among Secondary School Students", The Journal of International Social Research, Vol 2(9), Pp.539549.

Basu, A., dan M. Virick (2008),'Assesing Entrepreneurial Intentions Amongst Student: A Comparative Study", http://nciia.org/conf08/assets/pub/basu2.pdf.

Brandstatter, H, (2010),"Personality Aspect of Entrepreneurship: A Look at Five MetaAnalyses", Personality and Individual Differences, doi:10.1016/j.paid.2010.07. 007

Brice Jr, J, (2004),'The Role of Personality Dimensions on the Formation of Entrepreneurial Intentions", USASBEProceedings, pp. I-8.

Carr, J.C., dan J.M. Sequeira (2007),"Prior Family Business Exposure as Intergenerational Influence and Entrepreneurial Intent: A Theory of Planned Behavior Approach", Journal of Business Research, Vol.60. pp.1090-1098.

Chin, W.W., B.L. Marcolin, dan P.R. Newsted, (1996),"A Partial Least Squares Latent Variable Modeling Approach for Measuring Interaction Effects: Result from A Monte Carlo Simulation
Study and Voice Mail Emotion / Adoption Study", Proceeding of the Seventeenth International Converence of Information System, I6-I8 December, Ohio, Pp.2I-4I.

Cooper, D.R., dan P.S. Schindler, (2008), Business Research Methods, I0thed, New York, NY: McGraw-Hill/Irwin.

Faul, F., E. Erdfelder, A-G. Lang, dan A. Buchner, (2007),"G*Power 3: A Flexible Statistical Power Analysis Program For The Social, Behavioral, and Biomedical Sciences", Behavior Research Methods, Vol. 39, pp.175-191.

Fitzsimmons, J.R., dan E. J. Douglas, (2006),'The Impact of Overconvidence on Entrepreneurial Intensions", Regional Frontiers of Entrepreneur Research, Pp.466-479.

Gadar, K, dan N.K.Y. Yunus, (2009),'The Influence of Personality and Socio-Economic Factors on Female Entrepreneurship Motivations in Malaysia", International Review of Business Research Papers, Vol 5(I), January, Pp. I49-162.

Gefen, D., dan D. Straub, (2005),“A Practical Guide to Factorial Validity Using PLS-Graph: Tutorial and Annotated Example", Communication of Association for Information System, Vol.16, pp.91-109.

Hair, J.F., W.C. Black, B.J. Babin, R.E. Anderson, dan R.L. Tatham, (2006), Multivariate Data Analysis, 6thed, Upper Saddle River, NJ: Pearson Educational, Inc.

Hansmann, K.W., dan C.M. Ringle, (2004), SmartPLS Manual, University of Hamburg, Hamburg.

Hasanuddin., J. Kristofel, P. I. Mahatrisni, N.T Winasis, dan B. Satrio (20II), Anxieties/Desires, 90 Insight for Marketing to Youth, Women, Netizen in Indonesia, Gramedia Pustaka Utama, Jakarta.

Indarti, N., R. Rostiani, dan T. Nustiti, (2010), "Underlying Factors of Entrepreneurial Intentions among Asian Students", The South East Asian Journal of Management, Vol. IV (2), PP.I43-I59.

Ismail, M., S.A. Khalid, M. Othman, K. Jusoff, N.A. Rahman, K.M. Kassim, and R.S. Zain, (2009), "Entrepreneurial Among Malaysian Undergraduates", International Journal of Business and Management, Vol 4(I0), Pp54-60. 
John, O.P., dan S. Srivastava (1999), The Big-Five Trait Taxonomy: History, Measurement, and Theoretical Perspectives, University of California at Berkeley, U.S.A.

Krueger, N.F., M.D. Reilly, dan A.L. Carsrud, (2000),"Competing Models of Entrepreneurial Intentions", Journal of Business Venturing, Vol. I5,pp.4 I I-432.

Kumar, R., dan C. Uzkurt, (2009), "Investigating the Effects of Self Efficacy on Innovativeness and the Moderating Impact of Cultural Dimensions", Journal of International Business and Cultural Studies, http://www.aabri.com/manuscripts/I063I.pdf

Li, W., (2006),'Entrepreneurial Intention among International Students: Testing a Model of Entrepreneurial Intention", http://usasbe.org/knowledge/ proceedings/ proceedingsDocs/USASBE2006proceedingsLi\%20-\%20Internat.pdf

Luthans, F., dan E. S. Ibrayeva, (2006), "Entrepreneurial Self-Efficacy in Central Asian Transition Economics: Quantitative and Qualitative Analyses", Journal of International Business Study, No. 37, pp.92-110.

Muller, S.L., dan M.C. Dato-On, (2008), "GenderRole Orientation as A Determinant of
Entrepreneurial Self-Efficacy", Journal of Developmental Entrepreneurship, Vol. I3(I),pp.3-20.

Nasurdin, A.M., N.H. Ahmad, dan C.E. Lin, (2009), "Examining a Model of Entrepreneurial Intentions among Malaysians Using SEM Procedure", European Journal of Scientific Research, Vol.33(2), pp.365-373.

Pruett, M., R. Shinnar, B. Toney, F. Llopis, dan J. Fox, (2009), "Explaining Entrepreneurial Intentions of University Students: a CrossCultural Study", International Journal of Entrepreneurial behavior \& Research, Vol. I5(6), pp.57I-594.

Tenenhaus, M., V.E. Vinci, YM. Chatelin and C. Lauro (2005), "PLS Path Modeling", Computational Statistics \& Data Analysis, Vol.48, pp. I59-205.

Thun, B, dan E.K. Kelloway, (2006), "Subjective Norms and Lemonade Stands: The Effects of Early Socialization and Childhood Work Experiences on Entrepreneurial Intent", ASAC, Pp.II0-I22.

Zhao, H., dan S.E. Seibert, (2006), "The Big Five Personality Dimensions and Entrepreneurial Status: A Meta-Analytical Review", Journal of Applied Psychology, Vol.9I(2), pp.259-27I. 